\title{
The Mutualist Laccaria bicolor Expresses a Core Gene Regulon During the Colonization of Diverse Host Plants and a Variable Regulon to Counteract Host-Specific Defenses
}

\author{
Jonathan M. Plett, ${ }^{1,2}$ Emilie Tisserant, ${ }^{1}$ Annick Brun, ${ }^{1}$ Emmanuel Morin, ${ }^{1}$ Igor V. Grigoriev, ${ }^{3}$ Alan Kuo, ${ }^{3}$ \\ Francis Martin, ${ }^{1}$ and Annegret Kohler ${ }^{1}$ \\ ${ }^{1}$ Inra, UMR 1136 Inra-Université de Lorraine, Interactions Arbres/Microorganismes, Inra-Nancy, 54280 Champenoux, \\ France; ${ }^{2}$ Hawkesbury Institute for the Environment, University of Western Sydney, Richmond, NSW, Australia 2753; \\ ${ }^{3}$ Department of Energy Joint Genome Institute, Walnut Creek, CA 94598, U.S.A.
}

Submitted 13 May 2014. Accepted 17 September 2014.

The coordinated transcriptomic responses of both mutualistic ectomycorrhizal (ECM) fungi and their hosts during the establishment of symbiosis are not well-understood. This study characterizes the transcriptomic alterations of the ECM fungus Laccaria bicolor during different colonization stages on two hosts (Populus trichocarpa and Pseudotsuga menziesii) and compares this to the transcriptomic variations of $P$. trichocarpa across the same timepoints. A large number of $L$. bicolor genes $(\geq 8,000)$ were significantly regulated at the transcriptional level in at least one stage of colonization. From our data, we identify 1,249 genes that we hypothesize is the 'core' gene regulon necessary for the mutualistic interaction between $L$. bicolor and its host plants. We further identify a group of 1,210 genes that are regulated in a host-specific manner. This variable regulon encodes a number of genes coding for proteases and xenobiotic efflux transporters that we hypothesize act to counter chemicalbased defenses simultaneously activated at the transcriptomic level in $P$. trichocarpa. The transcriptional response of the host plant $\boldsymbol{P}$. trichocarpa consisted of differential waves of gene regulation related to signaling perception and transduction, defense response, and the induction of nutrient transfer in $\boldsymbol{P}$. trichocarpa tissues. This study, therefore, gives fresh insight into the shifting transcriptomic landscape in both the colonizing fungus and its host and the different strategies employed by both partners in orchestrating a mutualistic interaction.

Plants are constantly in contact with different types of fungi ranging from parasitic to endophytic to mutualistic. To guarantee survival, therefore, the plant must encode certain transcriptional programs that enable interaction with beneficial

The complete expression datasets are available in the National Center for Biotechnology Information's Gene Expression Omnibus database under accession number GSE62225 and GSE62226.

Corresponding author: A. Kohler; Telephone: +33 3833940 41; Fax: +33 3833940 69; E-mail: kohler@ nancy.inra.fr

* The $\boldsymbol{e}$-Xtra logo stands for "electronic extra" and indicates that seven supplementary tables and three supplementary figures are published online.

(C) 2015 The American Phytopathological Society mutualistic microbes and instigate resistance against pathogenic detrimental organisms (Newton et al. 2010). Fungi, such as the mutualistic ectomycorrhizal (ECM) fungi, likewise have evolved mechanisms to overcome, resist, or control these differing plant responses, in order to colonize root tissues (Brundrett 2009; Kloppholz et al. 2011; Plett et al. 2011, 2014a). The molecular mechanisms that enable an ECM fungus to colonize a range of host plants are not well-characterized, although recent work has begun to tease out the host genetic markers that facilitate the interaction between ECM fungi and host trees (Labbé et al. 2011; Tarkka et al. 2013).

We sought here to understand how L. bicolor, a generalist ECM fungus, tunes its transcriptomic response to multiple hosts during different physiological stages of colonization. Further, we analyzed the coordinated transcriptomic response of one host at the same stages. A number of molecular studies considering ECM mutualistic interactions have used L. bicolor as a model (Felten et al. 2009; Heller et al. 2008; Larsen et al. 2010, 2011; Martin et al. 2008; Plett et al. 2014b). These studies have emphasized the importance of different hormonally controlled developmental pathways (Felten et al. 2009; Plett et al. 2014b), the importance of glycine, glutamate, and allantoin in spurring the exchange of nutrients during the progression of the interaction between L. bicolor and its host plant (Larsen et al. 2010, 2011) and the metabolic differences in host response during compatible and incompatible mutualistic interactions (Tschaplinski et al. 2014). They have also identified a number of effector-like mycorrhiza-induced small secreted proteins (MiSSP) (Martin et al. 2008) that act to target plant signaling pathways to foster symbiosis (Plett et al. 2014a). Given the wide range of tissue ages and culture techniques used in these different studies, however, it is difficult to ascertain the transcriptomic specificity of the ECM fungus to different host plants or to determine if there is a stable 'core' gene regulon expressed independent of either host identity or colonization stage that serves as the genetic foundation for the symbiotic lifestyle. The response of the host plants under the same conditions is also lacking. Together, these data are critical in defining what mechanisms ECM fungi have evolved to communicate with a variety of plants and understanding how a receptive host plant (i.e., a plant with high percentage of colonized root tips) adapts to colonization by an ECM fungus.

In order to address these points, we consider here the transcriptional analysis of L. bicolor during the colonization pro- 
cess of two different host plants (Populus trichocarpa, an angiosperm, and Pseudotsuga menziesii, a gymnosperm) grown in the same conditions. Further, using the same RNA pool, we simultaneously characterized the transcriptomic response of $P$. trichocarpa. After the initial shift, the transcriptome of $L$. bicolor was quite stable across all stages of colonization, with the majority of genes showing small differences in transcriptional level between two and 12 weeks of colonization. Within the regulated genes in L. bicolor, $5.4 \%$ of all L. bicolor genes exhibited strict conservation of transcriptional control between both plant hosts, pointing to the possibility that these genes represent the necessary core set of genes that have evolved in L. bicolor to enable the mutualistic interaction with plants. Conversely, we denote a group of 1,210 genes $(5.2 \%$ of all $L$. bicolor genes) as the 'variable regulon' due to their differential regulation between angiosperm and gymnosperm hosts. These genes, therefore, may play a role in host-specific interactions. $P$. trichocarpa, meanwhile, exhibited only a small number of significantly regulated transcripts that varied greatly in their expression patterns across the different stages of colonization. This set of genes was characterized by a variety of genes associated with plant defenses and nutrient transport. These results open the door for future characterization of novel mutualistic signaling pathways associated with specific stages of host-fungal interactions.

\section{RESULTS}

\section{A timecourse of mycorrhizal root tip development.}

L. bicolor (Maire) P.D. Orton isolate S238N (originally isolated from a colonized root of Tsuga mertensiana [Di Battista et al. 1996]) has a strong positive influence on the growth of host plants (Le Tacon et al. 1992). In order to better understand this mutualistic colonization process, we chose, here, to define the different stages of colonization of newly rooted $P$. trichocarpa saplings by L. bicolor in a pot culture. Across

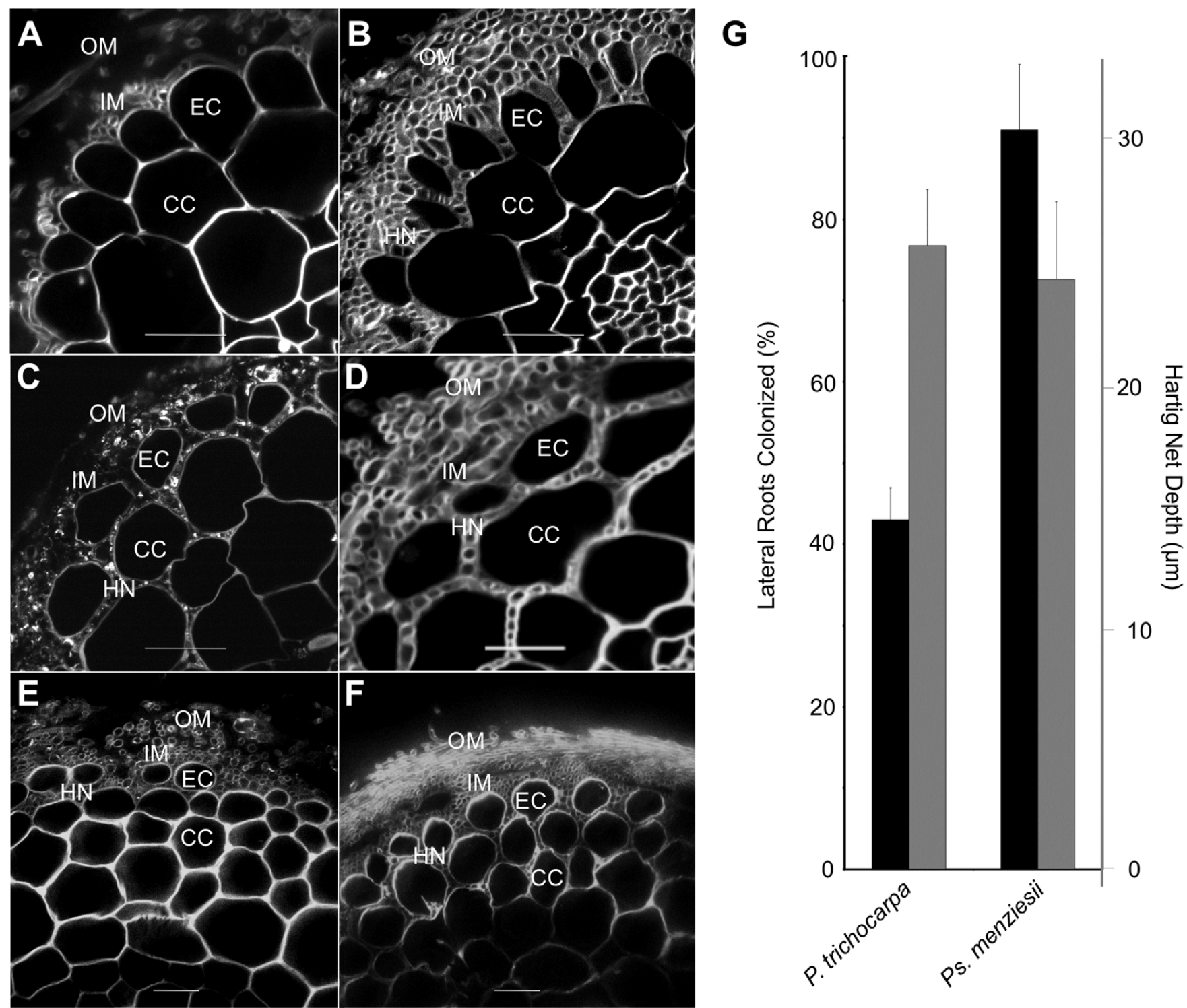

Fig. 1. The different stages of Laccaria bicolor root colonization. Cross section of A, a Populus trichocarpa lateral root after 2 weeks in contact with L. bicolor, showing the beginning of fungal aggregation on the root surface; $\mathbf{B}$, a $P$. trichocarpa lateral root after 4 weeks in contact with $L$. bicolor, showing the beginning of fungal penetration within the root; $\mathbf{C}$, a P. trichocarpa lateral root after 6 weeks in contact with L. bicolor, showing proliferation of the fungal Hartig net; and D, a P. trichocarpa lateral root after 12 weeks in contact with L. bicolor, showing a fully developed mantle and Hartig net. In comparison are the Pseudotsuga menziesiii root transverse cross sections of $\mathbf{E}$, early-stage and $\mathbf{F}$, late-stage mycorrhizal root tips. G, Comparison of the percent lateral roots colonized (black bars) and the depth of the Hartig net (gray bars, in $\mu \mathrm{m}$ ) between P. trichocarpa and Pseudotsuga menziesiii colonized by L. bicolor. All values \pm standard error. $\mathrm{OM}=$ outer mantle, $\mathrm{IM}=$ inner mantle, $\mathrm{HN}=$ Hartig net, $\mathrm{EC}=$ epidermal cell, $\mathrm{CC}=$ cortical cell; Bars $=10 \mu \mathrm{m}$. 
a 12-week period of time, the number of roots exhibiting fungal colonization increases continually and then levels off after 12 weeks (Tschaplinski et al. 2014). Microscopically, we were able to define the morphological events occurring at different points. After 2 weeks of contact, L. bicolor was beginning to aggregate on the surface of newly emerged short roots (Fig. 1A). After 4 weeks of contact between the two organisms, L. bicolor had formed a full mantle around the lateral roots and had begun to grow into the apoplastic space of the root (Fig. 1B). Typically, at this stage, fungal hyphae had surrounded the rhizodermal cells of the root. Through 6 weeks of contact, the fungus continued extending within the apoplastic space of the root to surround one to two layers of cortical cells (Fig. 1C). The final timepoint was at 12 weeks after putting the two organisms in contact. At this stage, very little had physically changed regarding the morphology of the colonized roots (Fig. 1D). Colonization of $P$. trichocarpa roots resulted in a significant increase in plant growth and lateral root density (Supplementary Fig. 1). Based on these morphological stages observed repeatedly over the course of multiple experiments over a two year time-frame, we would define the 2-week timepoint as the 'aggregation' stage, the 4-week timepoint as the 'penetration' stage, the 6-week timepoint as the Hartig net 'proliferation' stage, and the final, 'mature' mycorrhizal root tip stage at the 12-week timepoint. Faster colonization dynamics were observed in the interaction between L. bicolor and Pseudotsuga menziesii, with penetration occurring as early as 2 weeks after contact (Fig. 1E) and a fully established Hartig net at 6 weeks after contact (Fig. 1F).

In order to understand the molecular hallmarks of these different stages of mycorrhizal root development, we performed transcriptomic analyses of L. bicolor on P. trichocarpa roots at each of the different stages of colonization. To serve as a host comparison, we also analyzed the transcriptome of L. bicolor colonizing the roots of the gymnosperm Pseudotsuga menziesii under the same conditions, after 2, 4, and 6 weeks of colonization. This latter timepoint is functionally equivalent to 12 weeks of contact between P. trichocarpa and L. bicolor, as 6 weeks of contact between L. bicolor and Pseudotsuga menziesii results in a stable average of $90 \%$ lateral roots colonized by the fungus with a Hartig net depth similar to that of a mature L. bicolor-P. trichocarpa ectomycorrhizal root tip (Fig. 1G).

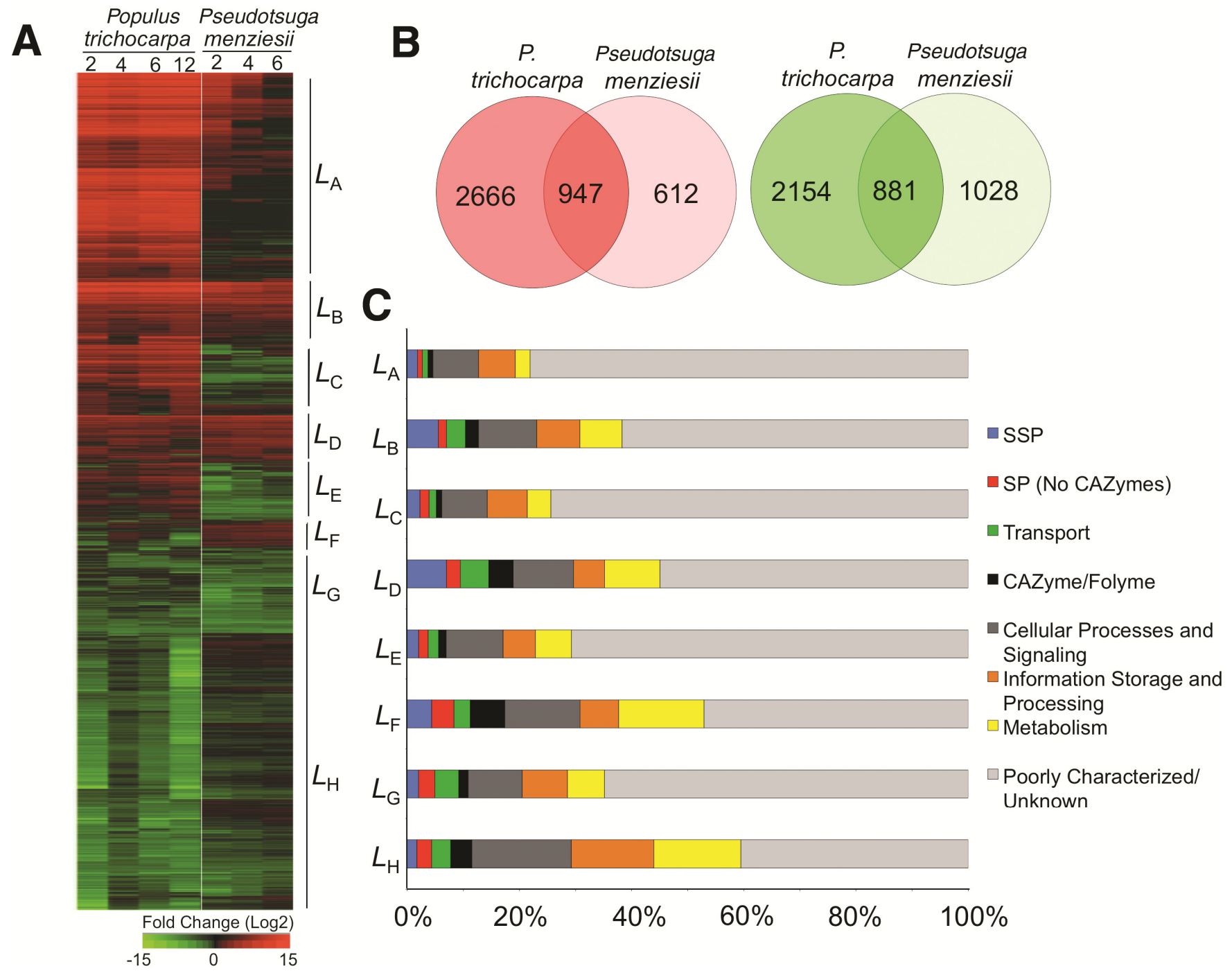

Fig. 2. Laccaria bicolor gene transcription in response to two different plant hosts. A, Hierarchical clustering of the log2-transformed data of significantly regulated genes of $L$. bicolor in contact with two plant hosts for different lengths of time. The heat map is annotated on the right side with the hierarchical groupings denoted $L_{\mathrm{A}}$ to $L_{\mathrm{H}}$. B, Venn diagram showing the overlap in the number of genes with significant elevated transcript abundance (red) and reduced transcript abundance (green) as compared with free-living mycelium. These diagrams do not include the number of genes that have an increased transcript presence at one timepoint and a repressed expression value at the second. $\mathbf{C}$, Functional classification of the genes found to be in each regulon. 


\section{L. bicolor responds with different transcriptomic intensities to angiosperm and gymnosperm hosts.}

We found that 8,644 genes were differentially regulated ( $\geq 2.5$ fold; $P<0.05$ ) in at least one developmental stage of the $L$. bicolor colonization of $P$. trichocarpa or Pseudotsuga menziesii. Globally, we found that L. bicolor colonization of $P$. trichocarpa resulted in a greater amplitude of gene regulation, as opposed to the amplitude of gene regulation during Pseudotsuga menziesii colonization (Fig. 2A; Supplementary Table 1). In the former pairing, the majority of genes exhibiting significant regulation during the fungal aggregation stage (2 weeks after contact) (Fig. $2 \mathrm{~A}$, regulons $L_{\mathrm{A}}$ and $L_{\mathrm{H}}$ ) maintained the same level of transcriptomic expression or repression through to the mature mycorrhizal root tip (12 weeks). In contrast, L. bicolor interaction with Pseudotsuga menziesii resulted in an initial burst of differential gene regulation, followed by a steady return to presymbiotic levels in the following timepoints of colonization (Fig. 2A). There were a number of L. bicolor genes that were significantly regulated in the same fashion, although not necessarily to the same amplitude, during the colonization of both hosts (Fig. 2B). This included a common set of 947 genes with increased transcript abundance and 881 genes with reduced transcript abundance. The group of genes exhibiting increased transcript abundance was characterized by a high percentage of poorly characterized genes or genes of unknown function, while the common genes with repressed levels of transcription were divided between annotated functions in cellular processes and signaling, information storage and processing, metabolism, and genes with unknown function (Fig. 2C). One class of genes that did not conform to the general trend of lower induction in the L. bicolorPseudotsuga menziesii interaction as compared with the $L . b i$ color-P. trichocarpa interaction were the carbohydrate active enzymes (CAZymes). In total, 60 CAZymes exhibited significantly increased transcript abundance during at least one stage of colonization in the former interaction as opposed to 53 genes in the latter interacting pair (Supplementary Fig. 2; Supplementary Table 2). Further, there was a greater number of CAZymes with significantly reduced transcript levels in the $L$. bicolor-P. trichocarpa interaction (117 downregulated genes) as compared with the L. bicolor-Pseudotsuga menziesii interaction (52 downregulated genes, e.g., GH16, GH24).

During the interaction between two organisms, the secretome is very important, as these proteins are responsible for communicating between the two partners as well as altering the environment around the invading organism (Martin and Kamoun 2012). We analyzed the modification of the different classes of secreted proteins within the significantly regulated genes of L. bicolor in contact with both hosts (Fig. 3A through D). In the L. bicolor-P. trichocarpa interaction, there were a larger number of MiSSP and, as seen with the CAZyme family as a whole, a smaller number of secreted CAZymes upregulated by colonization as compared with the L. bicolorPseudotsuga menziesii interaction (Fig. 3A and C). In the interaction with both hosts, there were a large number of secreted proteases that exhibited lower transcript abundance (Fig. 3B and D). From our data, we were able to annotate a new type of small secreted protein (SSP), i.e., the mycorrhizarepressed (Mr)SSP. These were SSP ( $<300$ amino acids) that exhibited significantly repressed levels of expression during the establishment of the mutualistic interaction. While a large portion of the MiSSP of L. bicolor were found to have no homologues or conserved domains with genes from other fungal genomes (52\% of MiSSP expressed during the L. bicolor$P$. trichocarpa interaction and $42 \%$ of MiSSP expressed during L. bicolor-Pseudotsuga menziesii [Fig. 3E]), we found that MrSSP had a higher level of conservation in the fungal tree of life. For example, $8 \%$ of MrSSP repressed during the L. bicolor-P.trichcarpa interaction have no known existing homologues in other fungal systems, while $31 \%$ of MrSSP repressed during the L. bicolor-Pseudotsuga menziesii interaction have no known homologues (Fig. 3E). These data would suggest that MrSSP are encoded by more conserved genes of unknown function within the fungal tree of life that either have no role or a detrimental role to the mutualistic lifestyle or which may control the growth of free-living hyphae.

\section{L. bicolor encodes a stable mutualistic core regulon.}

One group of genes, denoted as regulon groups $L_{\mathrm{B}}$ and $L_{\mathrm{D}}$ in Figure 2A, were characterized by equally high levels of expression at all timepoints in the interaction between L. bicolor and both of its hosts. Within this group, we found a small number of CAZymes (e.g., GH16 xyloglucan:xyloglucosyltransferase [protein ID 619909, 239682]; GH17 glucan 1,3- $\beta$-glucosidase [protein ID 296997]; GH18 chitinase [protein ID 310136 , 246840, 301747]; GH28 polygalacturonase [protein ID 612983, 613299], GH61 lytic polysaccharide monooxygenases (now AA9) [protein ID 299682]), a number of mycocypins, cytochrome P450s, and a terpene synthase. A number of transporters were also included in this group, namely, one ammonium transporter, an oligopeptide transporter, as well as major facilitator superfamily (MFS), amino acid, and sulfate transporters (Supplementary Table 3). There was a significant enrichment of MiSSP-coding genes in this group as opposed to the other regulons $\left(5.5 \%\right.$ in regulon $L_{\mathrm{B}}$ and $7 \%$ in regulon $L_{\mathrm{D}}$ as opposed to $2 \%$ of all genes tested [Table 1]; Fisher exact test $P<0.05$ ). MiSSP were significantly enriched for $L$. bicolor specific SSP as opposed to the genomic complement of L. bicolor SSP (2.7\% in regulon $L_{\mathrm{B}}$ MiSSP and $2.2 \%$ in regulon $L_{\mathrm{D}}$ MiSSP as opposed to $0.8 \%$ of all SSP annotated [Table 1]). The MiSSP within these two regulons included MiSSP7, MiSSP22, MiSSP31, MiSSP11.4, MiSSP7.6, MiSSP8, MiSSP17, MiSSP32, and MiSSP12. The presence of a core of genes whose expression patterns are maintained between very different host species and stages of colonization would suggest that these genes form the minimum basis of genes necessary to allow for the mutualistic lifestyle of L. bicolor.

\section{L. bicolor encodes a variable regulon with host-specific expression patterns.}

In addition to a set of genes whose expression was independent of host identity was a set of genes whose expression was found to be regulated in opposing manners when the two hosts were compared. These genes likely encode proteins that have host-specific roles. The majority of these genes were upregulated in the $L$. bicolor-P. trichocarpa interaction and repressed in the L. bicolor-Pseudotsuga menziesii symbiotic relationship (Fig. 2A, regulons $L_{C}$ and $L_{E}$ ). The role of the genes within the host-specific groups is difficult to interpret. This is due to the fact that genes from these groups have a high number of unknown or Laccaria-specific genes. For example, in regulon $L_{\mathrm{C}}, 45 \%$ of the genes regulated are Laccaria-specific and $34.7 \%$ genes of regulon $L_{\mathrm{E}}$ are specific to $L$. bicolor (Fig. 2A; Table 1). This concentration of L. bicolor-specific genes is a significant enrichment over the genomic complement of L. bicolor-specific genes (Table 1, 22.9\%). Within this group of 2,097 L. bicolor-specific genes (out of a total 8,644 regulated transcripts), 85 are SSP, 14 are secreted but $\geq 300$ aa, 136 have a pfam domain, and 42 a GenBank (nonredundant) hit (Supplementary Table 4). Of the remaining genes with annotated functions, several are peptidases (e.g., protein ID 436610, 299240, 709984) and lipases (e.g., protein ID 633622, 299240, 570409) that were found to be more highly expressed in the L. bicolor-P. trichocarpa interaction. We also found that 

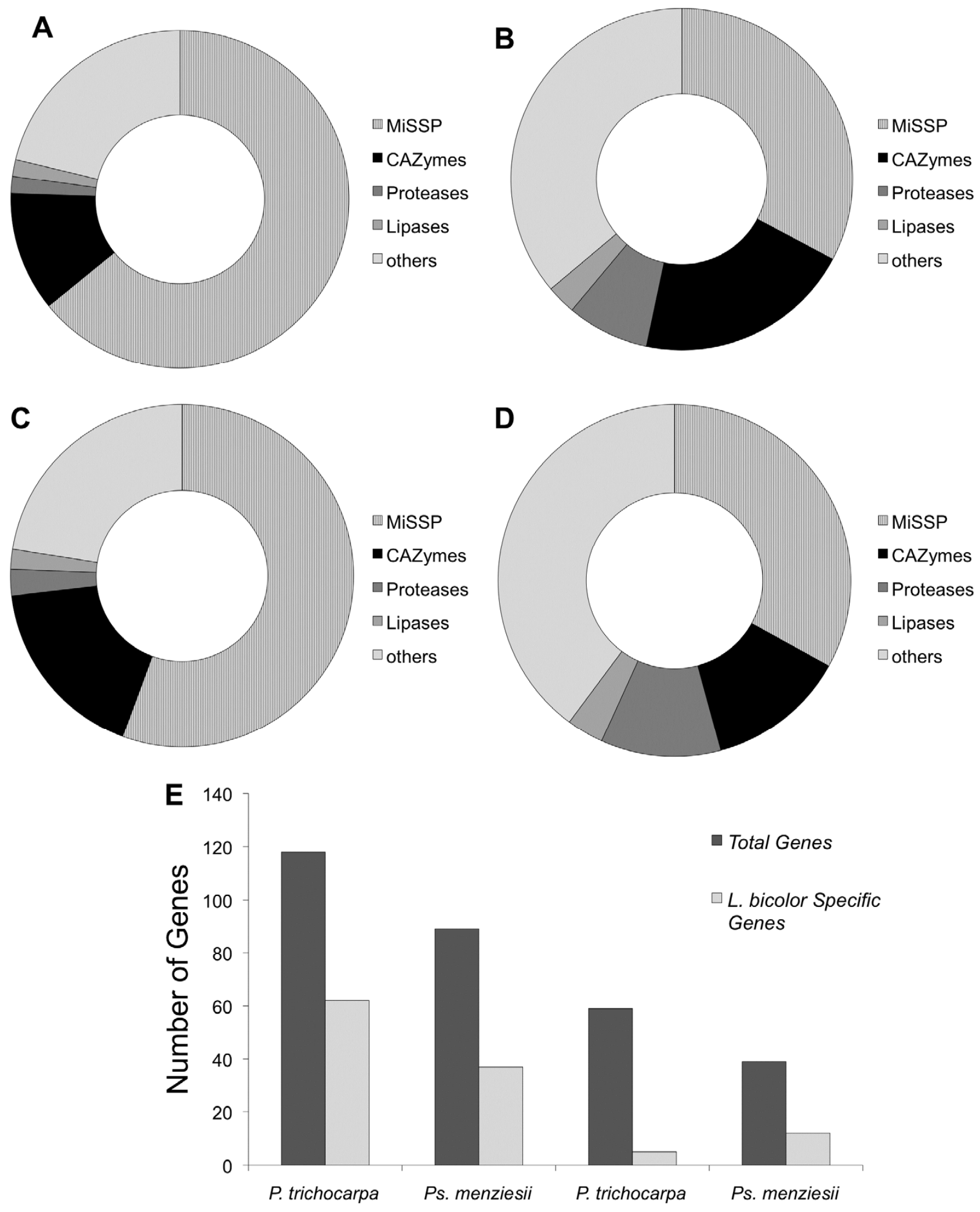

MiSSP Genes

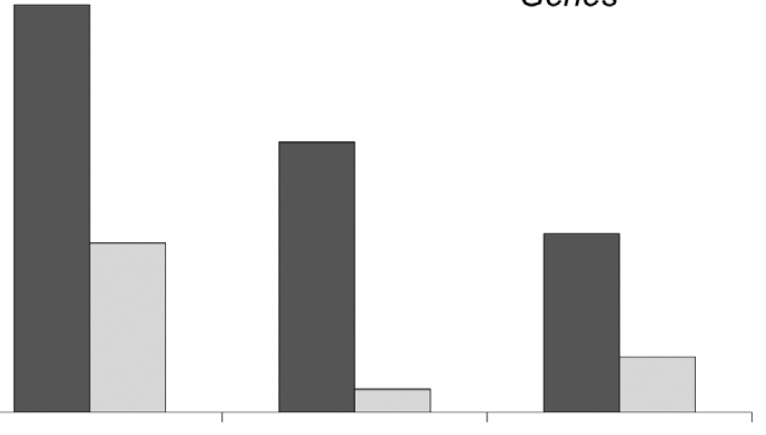

Ps. menziesii P. trichocarpa Ps. menziesii Fig. 3. Laccaria bicolor secretome during mutualistic symbiosis. A, Percentage of mycorrhiza-induced small secreted proteins (MiSSP), carbohydrate active
enzymes (CAZymes), proteases, lipases, and other secreted protein-coding genes significantly expressed when in contact with poplar or B, that are repressed using the same host. MrSSP = mycorrhiza-repressed SSP. The same graphics are shown for $\mathbf{C}$, upregulated and $\mathbf{D}$, downregulated genes in the response of $L$. bicolor to Pseudotsuga menziesii. E, Total number of expressed SSP compared with the number of SSP that have no homologue in other fungal genomes. $L$. bicolor-specific genes. A Markov chain clustering of predicted proteins from 49 fungal genomes was used. If a cluster contained only predicted proteins from $L$. bicolor, these proteins were considered to be Laccaria-specific. 
a number of MFS and xenobiotic transporters were activated (e.g., protein ID 151934, 314210, 314109, 577732), as were a number of Ankyrin proteins (e.g., protein ID 324492, 633186, 437613), a NACHT domain protein (protein ID 653763), and two ARMADILLO proteins (ID 442207, 489026). These results would suggest that $P$. trichocarpa, as the less receptive host, is confronting L. bicolor with a higher level of protein and toxin-based warfare than Pseudotsuga menziesii and that the variable $L$. bicolor regulon is responding with increased expression of detoxification transporters and with different proteins to degrade defensive plant-based proteins. These results reflect a similar trend observed during incompatible $L$. bicolor interactions with plant roots in which a larger complement of defensive metabolites was observed in the roots of plants poorly colonized by L. bicolor (Tschaplinski et al. 2014).

\section{The $P$. trichocarpa transcriptome evolves} during the colonization process by $L$. bicolor.

During the course of root colonization by an ECM fungus, the plant root undergoes a number of morphological changes from the cessation of growth to the alteration of plant cell-wall properties and, finally, the alternate control of wall-bound transporters to accommodate the new paradigm of nutrient fluxes inherent in mutualistic interactions. Therefore, we were interested in determining the global changes in host transcription during these different stages. We focused on $P$. trichocarpa due to the public availability of its genome (Tuskan et al. 2006). We identified 360 genes with significantly altered abundance during at least one stage of colonization ( $\geq 2.5$-fold regulation) (Fig. 4A; Supplementary Table 5). Unlike the relatively stable response of $L$. bicolor to $P$. trichocarpa across the stages of colonization considered here, the significantly regulated genes of $P$. trichocarpa displayed very variable transcriptional responses during colonization. Two major patterns of gene regulation are observed in the roots. One pattern involves genes that show increasing expression from the onset of fungal aggregation on the root through to proliferation of fungal hyphae within the root apoplastic space, after which they begin to decrease (Fig. 4A, regulons $P_{\mathrm{A}-\mathrm{D}}$ ). Included in this grouping of genes are stress- and defense-related genes, developmental genes, and genes annotated as transporters. The second pattern of gene expression involves genes that are repressed or not regulated in these same earlier timepoints but which become highly expressed in the mature mycorrhizal root tip (Fig. 4A, regulons $\left.P_{\mathrm{E}-\mathrm{G}}\right)$. Major functional classes of genes within these regulons are a number of hormone-response factors, genes in-

Table 1. Transcriptional regulation of genes specific to Laccaria spp. (Lacspecific) and genes coding for small secreted proteins (SSP), and Lac-specific SSP ${ }^{\mathrm{a}}$

\begin{tabular}{|c|c|c|c|}
\hline Cluster & \% Lac-specific ${ }^{b}$ & $\% \mathbf{S S P}^{\mathrm{c}}$ & $\begin{array}{c}\% \text { SSP } \\
\text { Lac-specific }\end{array}$ \\
\hline A & 44.3 & 1.8 & 1.2 \\
\hline B & 25.0 & 5.5 & 2.7 \\
\hline $\mathrm{C}$ & 45.4 & 2.3 & 1.6 \\
\hline $\mathrm{D}$ & 15.8 & 7.0 & 2.2 \\
\hline $\mathrm{E}$ & 34.7 & 2.0 & 1.4 \\
\hline $\mathrm{F}$ & 6.5 & 4.3 & 1.1 \\
\hline G & 20.8 & 2.0 & 0.3 \\
\hline $\mathrm{H}$ & 7.0 & 1.7 & 0.2 \\
\hline All regulated & 24.3 & 2.6 & 1.0 \\
\hline All genes on array & 22.9 & 2.0 & 0.8 \\
\hline
\end{tabular}

${ }^{a}$ Values in bold: enriched (Fisher exact test; $P$ value $<0.01$ ).

${ }^{\mathrm{b}}$ A Markov cluster algorithm of predicted proteins from 49 fungal genomes was used. If a cluster contained only predicted proteins from Laccaria spp., these proteins were considered as Lac-specific.

${ }^{c}$ Predicted secreted protein of less than 300 aa and not a protease, lipase, or carbohydrate active enzyme. volved in metabolic pathways and transport. Selected categories are discussed in more detail below. A further point of interest within this dataset was the fact that nearly $25 \%$ of the genes found to have 'increased' abundance over the course of the interaction between L. bicolor and P. trichocarpa were not actually upregulated over this time period. Rather, the expression of 84 of the 360 significantly regulated $P$. trichocarpa genes in roots undergoing colonization was maintained at the same or similar expression levels between 4 and 12 weeks of colonization (Fig. 4B; Supplementary Table 6), while the expression of these genes in uncolonized roots decreased over the same time interval. Therefore, L. bicolor appears to be maintaining the root in a more transcriptionally juvenile phase during the mutualistic interaction.

\section{Plant host perception, signaling, and defense relays activated by colonization.}

One of the key aspects of mutualistic interactions is the ability of the two partner organisms to perceive each other. During the fungal aggregation stage, we found very few $P$. trichocarpa genes related to either pathogen (e.g., resistance genes) or symbiotic detection (e.g., LysM receptor kinases). During the penetration and Hartig net proliferation stages, however, we observed a marked increase in the expression of different receptors and signaling proteins associated with plant-fungal interactions. These included NB-ARC domain-containing disease resistance genes (e.g., Potri.001G416900), cysteine-rich receptor-like kinases (e.g., Potri.011G029300), lectin protein kinases (e.g., Potri.011G28000), leucine-rich repeat receptors (e.g., Potri.003G138900), and a number of general protein kinases (e.g., Potri.013G030400) (Fig. 4C).

We were also interested in determining how perception of the fungal symbiont affected the defense signaling of $P$. trichocarpa. Defensive genes only showing increased expression during the early stages of colonization were homologous to PLIEOTROPIC DRUG RESISTANCE (PDR2, PDR5, PDR6; Potri.010G153800, Potri.002G188900, Potri.009G147100), to A. thaliana MLP423, a gene associated with defense responses triggered by the host upon pathogenic colonization (e.g., Potri.010G000200) (Ascencio-Ibáñez et al. 2008; Libault et al. 2007), and to $\beta$-glucosidases (e.g., Potri.001G-1500). Other than a very small number of genes (e.g., homologues to genes such as a reticuline oxidase induced by jasmonic acid [JA] [Pandey et al. 2005]), there were very few genes regulated that were associated with hormonal-based plant defenses at these early stages of colonization.

In mature mycorrhizal root tips (i.e., 12 weeks of colonization; regulons $P_{\mathrm{F}}$ and $P_{\mathrm{G}}$ ) (Fig. 4A), a striking shift in plant defense response was noted. Transcriptomically, from the beginning of the colonization of roots, the plant appeared to largely base its defensive program on the use of toxic secondary compounds - a tactic that was attenuated at the 12-week timepoint (Fig. 4A, regulons $P_{\mathrm{A}}$ and $P_{\mathrm{B}}$ ). These genes included germins (e.g., Potri.013G000500 [Wang et al. 2013]), a putative terpene synthase (homologous to A. thaliana TRP21, Potri.015G 032100), U-box/ARMADILLO genes (e.g., Potri.008G137700, Potri.015G031000), and senescence-related genes. At this later timepoint, we also observed the induction of a hormone-based defense response. Classically, three plant hormones (ethylene [ET], salicylic acid [SA], and JA) are associated with plant defenses against pathogenic attack. We found, here, that there are transcriptomic signatures of the ET and SA pathways induced in $P$. trichocarpa colonized roots. These included a number of ET-response factors (AP2/ERF transcription factors; e.g., Potri. 014G046600) and a number of genes normally associated with SA-induced signaling (e.g., homologues of A. thaliana WRKY33 [Potri.016G128300], WRKY40 [Potri.003G182200], WRKY41 


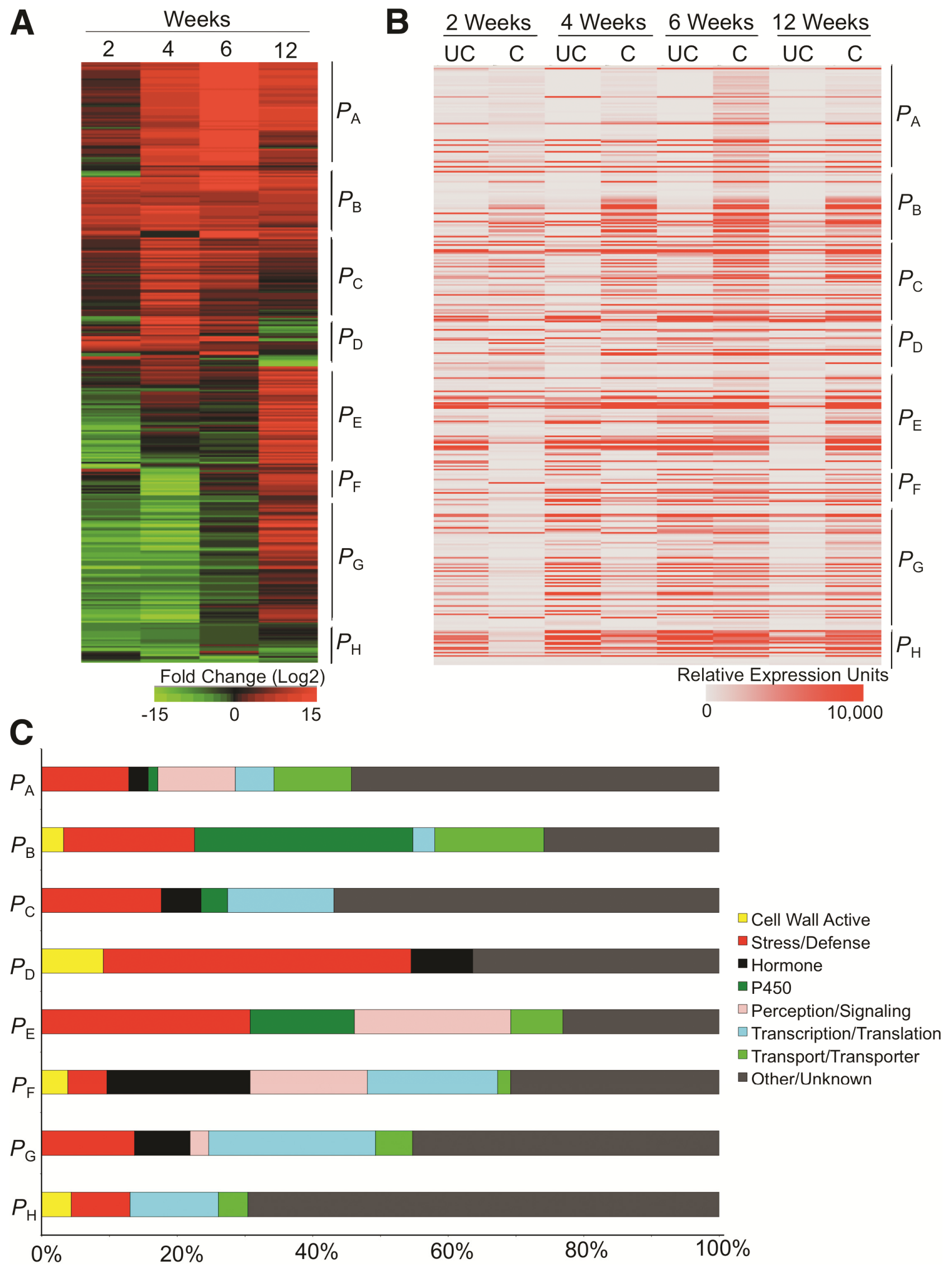

Fig. 4. Populus trichocarpa gene transcription alters radically in response to different stages of colonization. A, Hierarchical clustering of the log2-transformed data of significantly regulated genes of $P$. trichocarpa in contact with Laccaria bicolor. The heat map is annotated on the right side with the hierarchical groupings denoted $P_{\mathrm{A}}$ to $P_{\mathrm{H}}$. B, Mean expression map showing just the expression of genes in each sample tested. UC= uncolonized control; C $=$ colonized root. Functional classification of the genes found to be in each regulon. 
[Potri.001G092900]) (Birkenbihl et al. 2012; Li et al. 2004). Despite the overexpression of one known JA-induced gene (homologue of A. thaliana WRKY53 [Potri.003G138600), the majority of genes associated with JA that displayed altered transcript abundance are responsible for repression of JA response. Examples include the upregulation of JAZ domaincontaining genes (homologues of $A$. thaliana JAZ5 [Potri.001 G166200] and JAZ8 [Potri.011G083900] and homologues of A. thaliana WRKY41).

\section{Nutrient transporters form an integral component of the colonization transcriptome.}

Given the importance of nutrient transport to the mutualistic aspect of this interaction, we analyzed the expression of different annotated transporter classes in $P$. trichocarpa throughout the colonization process (Supplementary Table 7). Surprisingly, the transporters classically associated with mutualistic nutrient exchange were significantly regulated in $P$. trichocarpa during stages as early as fungal aggregation on the root and prior to the establishment of the full Hartig net. The expression of these genes peaked at 6 weeks after contact with the fungus but they were still very highly expressed in mature 12-week-old mycorrhizal roots. The genes in these expression regulons (Fig. 4A, $P_{\mathrm{A}-\mathrm{C}}$ ) included an amino acid transferase (Potri.013G095900), four SWEET transporters (Potri.019G030500, Potri.002G072600, Potri.002G072700, Potri.002G.072800), and three malate transporters (Potri.009G017900, Potri.001G217300, Potri.001G217400). Another set of transporters was only found to be upregulated in the late phases of the colonization process (Fig. 4A, regulons $P_{\mathrm{F}}$ and $P_{\mathrm{G}}$ ), including amino acid permeases (e.g., Potri.006G236000), an ABC transporter (Potri.017G074000), and lipid transporters (e.g., Potri.002G251000).

\section{DISCUSSION}

The presence of a foreign organism stably integrated or 'accommodated' within plant tissues, as in the interaction between mutualistic ECM fungi and the roots of different tree species, requires a remarkably fine-tuned response on the part of both the plant and the invading organism. Typically the interaction between mutualistic microbes and plants progresses from i) the recognition of the microbe to ii) an attempt by the microbe to overcome plant defense through iii) penetration of plant tissues by the microbe and, finally, iv) a trade in nutrient stores between the two organisms. Recognition of microbes is mediated by pathogen-associated molecular pattern membrane receptors and resistance proteins (Chinchilla et al. 2007; DeYoung and Innes 2006; Thomma et al. 2011). These receptors then induce a signaling cascade that either accommodates the organism or attempts to repulse it through defense reactions. In the interaction between mutualistic Rhizobia bacteria and legumes, these signal relay pathways induce gene activation dedicated to fostering the mutualistic organism (e.g., LysM receptor kinases and GRAS family transcription factors) (Kaló et al. 2005; Limpens et al. 2003; Madsen et al. 2003; Radutoiu et al. 2003; Smit et al. 2005), while the interaction between arbuscular mycorrhizal fungi and their hosts requires an active SYM pathway (Gobbato et al. 2012; Oldroyd 2013). Less is known about how signal perception and transduction elements are coordinated between ECM fungi and their hosts during the different stages of colonization.

The ECM fungal lifestyle is thought to have evolved within the fungal tree of life multiple times, arising from saprotrophic ancestors unable to colonize living tissues (Hibbett and Matheny 2009). Within the spectrum of ECM fungi, L. bicolor is considered a generalist fungus, as it can colonize plant hosts from both angiosperm and gymnosperm lineages (Wallenda and Kottke 1998). Therefore, L. bicolor is an ideal model to study how an ectomycorrhizal fungus is able to tune its response to different host trees. In the interaction between L. bicolor and P. trichocarpa or Pseudotsuga menziesii, we demonstrate that the colonization rate is much higher during the latter interaction as opposed to the former (Fig. 1E). This higher level of colonization with Pseudotsuga menziesii is accompanied by a lower level of transcriptomic change in L. bicolor, a reduced number of differentially expressed effector-like MiSSP and a higher number of CAZyme genes with increased transcript abundance as compared with the L. bicolor-P. trichocarpa interaction (Figs. 2 to 4 ). These data would suggest that $L$. bicolor has two different colonization approaches. On a gymnosperm host, the fungus uses a more enzymatically based technique of colonization, while the colonization of the angiosperm host necessitates the use of a more diversified effectorbased control of plant tissues combined with a much higher level of gene transcription to overcome plant defenses.

Within the L. bicolor transcriptome we found evidence for a conserved core of genes that were regulated at levels independent of host identity and of colonization stage during the interaction with host roots. A number of these genes, especially in relation to nutrient transport, have also been identified as being regulated in the interaction between L. bicolor and another poplar host, Populus tremuloides (Larsen et al. 2011). This would suggest that, upon perceiving the presence of a plant root, transcriptional alterations to these 1,249 genes in $L$. bicolor hyphae enters a set pattern regardless of the host present. Such strict regulation would suggest that these genes, together, form the transcriptional foundation necessary for $L$. $b i$ color to enter into symbiosis with a plant. The logical outcome of this hypothesis would be, therefore, that loss of one or several of these genes would prevent $L$. bicolor from colonizing a host plant. Such evidence has already been found with relation to L. bicolor colonization of P. trichocarpa (Plett et al. 2011). Within this core set of genes is the highly upregulated MiSSP7 gene. MiSSP7 is a 7-kDa protein that is secreted from fungal hyphae and internalized within plant cells, after which it localizes to the nucleus (Plett et al. 2011). Loss of MiSSP7 expression results in a drop in colonization potential of $P$. trichocarpa from $42 \%$ with wild-type L. bicolor to 1 to $5 \%$ with L. bicolor Amissp7 RNAi mutants. While the necessity of MiSSP7 has not been tested in the interaction between $L$. bicolor and Pseudotsuga menziesii, we would hypothesize that it has a similar role in negotiating symbiosis, as we have found that MiSSP7 is also taken up into root cells and localizes to the nucleus (J. M. Plett unpublished data). We also found a nitrate reductase within this core set of L. bicolor genes. Like MiSSP7, the L. bicolor nitrate reductase gene LbNRT2 is an essential factor in mycorrhizal formation (Kemppainen et al. 2009). Therefore, as these two examples demonstrate, loss of expression of even one of these core genes is sufficient to stop (or reduce the efficiency of) the mutualistic interaction, the other genes within this group are also likely important, both individually and as a group, in negotiating symbiosis with $P$. trichocarpa. The fact that the majority of the genes within this core are MiSSP and that these MiSSP exhibit an enrichment in the number of L. bicolor-specific genes would also suggest that they have evolved specific roles during the evolution of the Laccaria lineage for this purpose.

In pathogenic systems, fungal pathogenicity is heavily influenced by the response of the host with intrinsic host traits and host life history playing an important role in determining the outcome of the infection (Begon 2008; Dobson 2004; Ezenwa and Jolles 2011; Gervasi et al. 2013). In bacterial symbiosis, we see the same pattern with host-specific responses priming the 
bacterial symbiont metabolically and transcriptomically for successful tissue colonization (Kremer et al. 2013). Further, in obligate mutualism, the host environment leads to transcriptomic and genomic specialization of the mutualists (Ellers et al. 2012; Shigenobu et al. 2000; Van Ham et al. 2003; Xiao et al. 2013). During the accommodation of L. bicolor within P. trichocarpa root tissues, we find similar evidence of coordinated transcriptomic responses. This coordination in gene expression programs between both organisms is exemplified in the control of defense regulation. When L bicolor hyphae are just beginning to aggregate on the surface of $P$. trichocarpa roots to form the mantle and to grow in between the rhizodermal cells ( 2 weeks after contact between the two organisms), the plant host's defense tactics were characterized by an increase in chemically and enzymatically based responses (e.g., $\beta$-glucosidases, $P D R$, MLP423, TRP21) (Ascencio-Ibáñez et al. 2008; Libault et al. 2007) or in the detoxification of fungal toxins (e.g., cytochrome P450) (Kim et al. 2006). Increased production of defensive metabolites has been verified during this stage in the interaction (Tschaplinski et al. 2014). In response, the L. bicolor variable regulon codes for genes that could counteract this class of host defense by producing proteases and xenobiotic efflux transporters. As colonization then proceeds, when the fungal mantle is fully formed and fungal hyphae are well-established in the root apoplastic space (12 weeks of contact), a striking shift in host defense response was noted, with the increased expression of genes linked to ET and SA hormone signaling and a repression of JA-induced gene transcription. A similar shift in defense strategies and the effect on fungal colonization has been described in the interaction between L. bicolor and $P$. tremula $\times P$. alba (Plett et al. 2014b) and in the interaction between Pisolithus microcarpus and Eucaluptus globulus (Duplessis et al. 2005), between Piloderma croceum and Quercus robur (Tarkka et al. 2013), and between Piriformospora indica and A. thaliana (Camehl et al. 2009), suggesting a key role for ET signaling during ectomycorrhizal colonization of host tissues. As suggested for the chemical-based plant defenses, it is likely that L. bicolor actively attempts to control plant-based hormone signaling, as has been seen with the alteration of auxin signaling in plant hosts by L. bicolor (Felten et al. 2009). Rather than proteases and xenobiotic efflux transporters, however, this counterattack likely takes the form of fungal effector proteins that alter the biological activity of key aspects of the host hormonal pathways. Recently, it was found that the highly expressed effector protein MiSSP7 of L. bicolor is able to be taken up into host cells, in which it localizes to the nucleus (Plett et al. 2011) and interacts with two JA transcriptional repressors (PtJAZ5 and PtJAZ6) (Plett et al. 2014a). The interaction between the effector and these repressors leads to a reduction in the transcription of a subset of JA marker genes, thereby demonstrating that L. bicolor is actively countering host hormonal defenses. There is also evidence for such a mechanism of control in other model systems. For example, the ECM fungus Pisolithus tinctorius controls host auxin signaling through the use of the hypaphorine effector (Reboutier et al. 2002). The distantly related mutualistic fungus Rhizophagus irregularis uses an effector protein to target and silence part of the host ET pathway (Klopholz et al. 2011). In pathogenic relationships, a range of effectors target plant JAZ proteins and JA receptors to alter the outcome of JA-induced transcription (Kazan and Lyons 2014; Mukhtar et al. 2011; Weiler et al. 1994). Therefore, as the host defense strategies change over the course of the interaction with L. bicolor, our results would suggest that they are counteracted in the fungus by the expression of proteases or of MiSSP.

Our results concerning the transcriptomic interplay between SA and JA pathways also support a developing theme within the interaction between ECM fungi and their host plants. Pre- viously reported work with $L$. bicolor and $P$. trichocarpa shows that JA inhibits L. bicolor proliferation in plant tissues (Plett et al. 2014a) and has demonstrated that L. bicolor also has the capability to take metabolites secreted from $P$. trichocarpa roots during colonization and catabolize them into SA (Tschaplinski et al. 2014). We now present further evidence that SA-marker genes are highly upregulated in roots undergoing colonization, while the majority of JA marker genes are repressed. Hormone analysis has found a similar induction of SA in the interaction between Paxillus involutus and Populus $x$ canescens (Luo et al. 2009), and it has been shown to improve colonization of Capsicum annuum by the endophyte Penicillium resedanum LK6 (Khan et al. 2013), while SA levels inhibit root colonization by arbuscular mycorrhizal fungi (Herrera Medina et al. 2003). This is different from model biotrophic interactions in which JA signaling is increased in plant tissues at the expense of SA-induced gene regulation (Gimenez-Ibanex et al. 2014; Jiang et al. 2013; Mukhtar et al. 2011; Weiler et al. 1994; Xu et al. 2011). Our results, presented here, combined with past published findings gives further credence to the hypothesis that SA favors, or at least is not detrimental to, ECM mutualistic interactions while JA is inhibitive to the relationship.

Our results also give us a glimpse into the transcriptional response of $P$. trichocarpa during these different phases of colonization and enable us to compare host response with the same fungal symbiont in the closely related $P$. tremuloides (Larsen et al. 2011) and in the gymnosperm Pinus sylvestris (Heller et al. 2008). Similar to what has been found in the interaction between $L$. bicolor and P. tremuloides, we show that nutrient transporters and amino acid metabolism are two important metabolic pathways induced at the transcriptional level (Larsen et al. 2011). We are able to show here, however, that the induction of these transporters and metabolic pathways occurs surprisingly early in the interaction-as early as the aggregation stage, before the establishment of the Hartig net (Fig. 4). This would suggest that nutrient exchange between the two partner organisms is occurring at a very early stage of the interaction. We also observed striking differences in the host reaction of $P$. trichocarpa and Pinus sylvestris to L. bicolor (Heller et al. 2008). Contrary to the P. trichocarpa host, early stages of the interaction between Pinus sylvestris and L. bicolor (i.e., aggregation stage) resulted in a transcriptional repression of most nutrient transporters and an induction of cellular defense genes (Heller et al. 2008). The majority of defense response genes were observed in the later stages of $P$. trichocarpa-L. bicolor interaction, while this class of genes was attenuated in mature mycorrhizal root tips in the interaction between Pinus sylvestris and L. bicolor (i.e., functional mycorrhizal root tips) (Heller et al. 2008). Similar to the P. trichocarpa host, discrete signaling pathways and cell-wall modifying enzymes were induced during the intermediate stages of colonization (i.e., fungal accommodation stage). These results would suggest that, while the genes necessary to accommodate the fungus within the plant tissue are similar between the two host lineages, gymnosperm and angiosperm hosts have very different genetic responses to the initial challenge by $L$. bicolor and they use different pathways to maintain functioning mycorrhizal root tips.

Therefore, we have characterized the whole genome transcriptomic responses of L. bicolor to two different hosts. Further, we characterize the coordinate gene expression in one of these hosts, $P$. trichocarpa. While there is a large degree of overlap in the transcriptomic reaction of L. bicolor to both an angiosperm and a gymnosperm host, L. bicolor displays an increase in the variety of MiSSP differentially expressed and repression of a larger number of CAZymes when colonizing 
P. trichocarpa as compared with Pseudotsuga menziesii. This may suggest that colonization of gymnosperm roots requires a more physical manipulation of the host to assure colonization while colonization of an angiosperm host requires a broader level of host manipulation through the use of more MiSSP effector proteins. We have defined a core set of 1,249 genes encoded by $L$. bicolor that are likely necessary for mutualistic lifestyle, as loss of even one of these genes (i.e., MiSSP7 [Plett et al. 2011]) leads to the loss of the mutualistic lifestyle for L. bicolor. These results further the concept that there is a complex interplay between the protein receptors of the plant and the role of mutualistic effectors in defining the plants with which ECM fungi will be able to form a mutualistic relationship. Finally, we show that the host plant has a narrow selection of genes that respond in a manner that is very dependent on the stage of fungal colonization. Especially apparent within this set of genes is the coordinated cycling of chemical- and hormonal-based defense signaling during fungal in-growth within plant tissues. These results further clarify the molecular events that are necessitated during the interaction between mutualistic fungal symbionts and their host plants.

\section{MATERIALS AND METHODS}

\section{Plant growth conditions.}

For colonization experiments, Laccaria bicolor innoculum was grown on a substrate of peat moss/vermiculite (3:1) dampened with liquid Pachlewski medium (2.7 $\mathrm{mM}$ di-ammonium tartrate, $7.3 \mathrm{mM} \mathrm{KK_{2 } \mathrm { PO } _ { 4 } , 2 . 0 \mathrm { mM } \mathrm { MgSO }} \cdot 7 \mathrm{H}_{2} \mathrm{O}, 13 \mathrm{mM}$ maltose, $110 \mathrm{mM}$ glucose, $2.9 \mu \mathrm{M}$ thiamine- $\mathrm{HCl}$, and $1 \mathrm{ml}$ of trace-element stock solution Kanieltra) for 3 months. Prerooted stem cuttings of Populus trichocarpa (rooted for 1 week in a solution of $2.5 \mathrm{mM} \mathrm{KNO}_{3}, 0.8 \mathrm{mM} \mathrm{KH}_{2} \mathrm{PO}_{4}, 1 \mathrm{mM} \mathrm{MgSO}_{4} \cdot 7$ $\mathrm{H}_{2} \mathrm{O}, 2.3 \mathrm{mM} \mathrm{Ca}\left(\mathrm{NO}_{3}\right)_{2} \cdot 4 \mathrm{H}_{2} \mathrm{O}, 23 \mu \mathrm{M} \mathrm{H} \mathrm{H}_{3} \mathrm{BO}_{3}, 4.6 \mu \mathrm{M}$ $\mathrm{MnCl}_{2} \cdot 4 \mathrm{H}_{2} \mathrm{O}, 0.4 \mu \mathrm{M} \mathrm{ZnSO}_{4} \cdot 7 \mathrm{H}_{2} \mathrm{O}, 0.09 \mu \mathrm{M}\left(\mathrm{NH}_{4}\right)_{2} \mathrm{MoO}_{4}$, $0.18 \mu \mathrm{M} \mathrm{CuSO}_{4} \cdot 5 \mathrm{H}_{2} \mathrm{O}, 20 \mu \mathrm{M}$ FeNaEDTA, pH 5.8) or 1week-old seedlings of Pseudotsuga menziesii were planted in a 9:1 mixture ( $\mathrm{vol} / \mathrm{vol})$ of Terra-Green (a calcined attapulgite clay supplied by Turf-Pro, Wallingford, U.K.) and L. bicolor inoculum. Each pot was given $20 \mathrm{ml}$ of a dilute nutrient solution $\left(0.8 \mathrm{mM} \mathrm{KNO} \mathrm{KN}_{3}, 0.8 \mathrm{mM} \mathrm{Ca}\left(\mathrm{NO}_{3}\right)_{2} \cdot 4 \mathrm{H}_{2} \mathrm{O}, 0.3 \mathrm{mM}\right.$ $\mathrm{NaH}_{2} \mathrm{PO}_{4}, 0.3 \mathrm{mM} \mathrm{MgSO} \cdot \cdot 7 \mathrm{H}_{2} \mathrm{O}$, and $20 \mu \mathrm{l}$ of trace-element solution Kanieltra per liter of solution) weekly. To determine the percent of $P$. trichocarpa roots colonized by L. bicolor over time, plants were destructively harvested at 2, 4, 6, and 12 weeks after being put into contact with $L$. bicolor, the root system was carefully washed clean of substrate, and the top third of the root system, in which most L. bicolor mycorrhizal root tips are found, was analyzed for the percentage of lateral roots colonized. This was performed by taking four random selections from this portion of the root mass, counting 25 lateral roots from each sample, and scoring them as mycorrhizal root tips or uncolonized root tips, using a Nikon SMZ-2T stereomicroscope (Nikon Instruments Europe B.V., Amsterdam). Four biological replicates (i.e., at least four individual plants) per timepoint were analyzed for colonization potential. The colonization experiment was replicated twice (technical replicate) under climate-controlled greenhouse conditions, maintaining a 16-h photoperiod and a temperature of $22^{\circ} \mathrm{C}$ during the day. To act as a comparison, Pseudotsuga menziesii plants undergoing colonization were treated identically and were harvested after 2, 4, and 6 weeks (a timepoint corresponding to when nearly the entire root system of Pseudotsuga menziesii is colonized by L. bicolor and the Hartig net is fully formed) to determine the percentage of the root system that had been colonized by L. bicolor.

\section{Sampling procedure.}

Tissues used for transcriptomic profiling were taken from root systems of $P$. trichocarpa $2,4,6$, and 12 weeks after contact with the fungus and from Pseudotsuga menziesii after 2, 4, and 6 weeks of colonization. Plants were destructively harvested at the same time of day to avoid confounding effects of circadian rhythm, their roots were washed of the substrate, and roots were observed using a Nikon SMZ-2T stereomicroscope (Nikon Instruments Europe B.V.). For 2-week samples, only roots that exhibited fungal mycelia attached to the root surface were sampled and frozen immediately in liquid nitrogen. For 12-week samples (or 6-week samples for Pseudotsuga menziesii), only roots that had a developed fungal mantle were sampled and frozen in liquid nitrogen. For each timepoint taken, plant host roots grown in the same substrate and with the same nutrient regime but without fungus were harvested to act as a control for transcriptomic analyses. L. bicolor freeliving mycelium grown on a medium containing agar and the nutrient solution used on the plants was used as the control tissue for L. bicolor. This control was used because L. bicolor grown in the Terra Green substrate could not be harvested in sufficient quantity for RNA extraction and transcriptomic analysis.

For microscopy analysis, roots that were at the same stage of colonization as used for transcriptomic samples were taken and fixed in ice-cold $4 \%$ paraformaldehyde. Infiltration of the fixative was aided by placing the samples under vacuum for $1 \mathrm{~h}$, followed by at least $24 \mathrm{~h}$ at $4^{\circ} \mathrm{C}$.

\section{Microscopy and Hartig net development measurements.}

Fixed tissues were used for all microscopic analysis. Following fixation, as described above, samples were washed twice in $1 \times$ phosphate buffered saline, $\mathrm{pH} 7.4$, and were then embedded in $6 \%$ (wt/vol) agarose. Sections (25 to $30 \mu \mathrm{m}$ thick) of the mycorrhizal roots were taken using a Leica 1200 series vibratome. Attention was paid to always take sections in the middle of the colonized root (approximately $2 \mathrm{~mm}$ from the root apex) to ensure the ability to compare the development of the Hartig net between samples. The development of the Hartig net is defined here as the depth of penetration within the apoplastic space between the rhizodermal cells of the root. The depth of penetration was determined using ImageJ analysis of our microscopic images. The data presented in this paper for the development of the Hartig net is the average of at least three biological replicates and a minimum of five technical replicates from each sample.

\section{RNA extraction and amplification.}

Four biological replicates between 50 to $100 \mathrm{mg}$ of tissues harvested, as described above, were used for RNA extraction for each timepoint. Total RNA extraction was performed using the RNAeasy kit (Qiagen, Courtaboeuf, France) per the manufacturer's instructions, with the addition of $25 \mathrm{mg}$ of polyethylene glycol 8000 per milliliter of RLC buffer (RNeasy, Qiagen) to the extraction solution. An on-column DNA digestion step with DNAse I (Qiagen) was also included to avoid DNA contamination. RNA quality was verified by Experion HighSens capillary gels (Bio-Rad, Marnes-la-Coquette, France). As mycorrhizal tissues are very recalcitrant to RNA extraction, quantities of RNA recovered were too low for quantities needed for either oligoarray or RNAseq analysis. Therefore, we amplified the RNA using the Clonetech SMARTer amplification kit (Ozyme, St Quentin en Yvelines, France), according to manufacturer's instructions. For Pseudotsuga menziesii mycorrhizal root tips, we followed only the transcriptional variation of $L$. bicolor, using oligoarrays for three independent biological replicates. 
Whole-genome oligoarray and bioinformatic data analysis.

Two oligoarrays were used in this study. The 4-plex Laccaria bicolor S238N whole genome expression array (GPL14641) and the Populus trichocarpa 12-plex whole genome expression array (GPL13485), both manufactured by NimbleGen Systems Limited (Madison, WI, U.S.A.). Single-dye labeling of samples, hybridization procedures, and data acquisition were performed at the NimbleGen facilities (Reykjavik, Iceland), following their standard protocol. Three or four biological replicates were performed for each condition. Microarray probe intensities were normalized across chips, using the ARRAYSTAR software (DNASTAR, Madison, WI, U.S.A.). Natural logtransformed data were calculated and were subjected to the CyberT statistical framework (Baldi and Long 2001), using the standard $t$-test unpaired two conditions data module. Benjamini-Hochberg multiple-hypothesis testing corrections with false discovery rate were used. Before transcripts were declared present, the signal-to-noise threshold (signal background) was calculated based on the mean intensity of random probes present on the microarray. Cut-off values for signal intensity (three times the mean intensity of random probes) were then subtracted from the normalized intensity values. The highest signal intensity values observed on these arrays were approximately 65,000 arbitrary units. Signals below the cut-off values were assigned a signal intensity value of 1 . For major categories of genes found to be significantly regulated, we plotted gene fold change as determined by oligoarray results against fold change as determined by RNA sequencing by Tschaplinski and associates (2014) (Supplementary Fig. 3). In all four categories analyzed, a significant correlation between the two techniques was found.

To detect L. bicolor-specific genes, each protein of 49 fungal genomes was aligned against every other protein, using BLASTP. The protein was then assigned to a cluster, with or without other proteins, using the Markov cluster algorithm based on alignment score. The resulting sets of mutually exclusive clusters were then filtered for those whose members were solely from L. bicolor and not from any of the other 48 fungal species.

The complete expression datasets are available as series (accession number GSE62225 and GSE62226 at the Gene Expression Omnibus at the National Center for Biotechnology Information website.

\section{ACKNOWLEDGMENTS}

This work was supported by the European Commission within the Project ENERGYPOPLAR (FP7-211917), and the ANR project FungEffector (to F. Martin). This research was also funded by the U.S. Department of Energy Genomic Science Program (Science Focus Area 'Plant-Microbe Interfaces') under contract DE-AC05-00OR22725. F. Martin's research group is part of the Laboratory of Excellence ARBRE (ANR-11-LABX0002-01). The work conducted by the U.S. Department of Energy Joint Genome Institute by I. V. Grigoriev, and A. Kuo is supported by the Office of Science of the U.S. Department of Energy under contract number DEAC02-05CH11231.

\section{LITERATURE CITED}

Ascencio-Ibáñezm, J. T., Sozzani, R., Lee, T. J., Chu, T. M., Wolfinger, R. D., Cella, R., and Hanley-Bowdoin, L. 2008. Global analysis of Arabidopsis gene expression uncovers a complex array of changes impacting pathogen response and cell cycle during geminivirus infection. Plant Physiol. 148:436-454.

Baldi, P., and Long, A. D. 2001. A Bayesian framework for the analysis of microarray expression data: Regularized t-test and statistical inferences of gene changes. Bioinformatics 17:509-519.

Begon, M. 2008. Effects of host diversity on disease dynamics. Pages 12 30 in: Infectious Disease Ecology: Effects of Ecosystems on Disease and of Disease on Ecosystems. R. S. Ostfeld, F. Keesing, and V. T.
Eviner, eds. Princeton University Press, Princeton, NJ, U.S.A.

Birkenbihl, R. P., Diezel, C., and Somssich, I. E. 2012. Arabidopsis WRKY33 is a key transcriptional regulator of hormonal and metabolic responses toward Botrytis cinerea infection. Plant Physiol. 159:266285.

Brundrett, M. C. 2009. Mycorrhizal associations and other means of nutrition of vascular plants: Understanding the global diversity of host plants by resolving conflicting information and developing reliable means of diagnosis. Plant Soil 320:37-77.

Camehl, I., Sherameti, I., Venus, Y., Bethke, G., Varma, A., Lee, J., Oelmüller, R. 2009. Ethylene signalling and ethylene-targeted transcription factors are required to balance beneficial and nonbeneficial traits in the symbiosis between the endophytic fungus Piriformospora indica and Arabidopsis thaliana. New Phytol. 185:1062-1073.

Chinchilla, D., Zipfel, C., Robatzek, S., Kemmerling, B., Nürnberger, T., Jones, J. D. G., Felix, G., and Boller, T. 2007. A flagellin-induced complex of the receptor FLS2 and BAK1 initiates plant defense. Nature 448:497-500.

DeYoung, B. J., and Innes, R. W. 2006. Plant NBS-LRR proteins in pathogen sensing and host-defense. Nat. Immunol. 7: 1243-1249.

Di Battista, C., Selosse, M.-A., Bouchard, D., Stenström, E., and Le Tacon, F. 1996. Variations in symbiotic efficiency, phenotypic characters and ploidy level among different isolates of the ectomycorrhizal basidiomycete Laccaria bicolor strain S238. Mycologia 100:1315-1324

Dobson, A. 2004. Population dynamics of pathogens with multiple host species. Am. Nat. 164:S64-S78.

Duplessis, S., Courty, P. E., Tagu, D., Martin, F. 2005. Transcript patterns associated with ectomycorrhiza development in Eucalyptus globulus and Pisolithus microcarpus. New Phytol. 165:599-611.

Ellers, J., Kiers, T. E., Currie, C. R., McDonald, B. R., and Visser, B. 2012. Ecological interactions drive evolutionary loss of traits. Ecol. Lett. 15:1071-1082.

Ezenwa, V. O., and Jolles, A. E. 2011. From host immunity to pathogen invasion: The effects of helminth coinfection on the dynamis of microparasites. Integr. Comp. Biol. 51:540-551.

Felten, J., Kohler, A., Morin, E., Bhalerao, R. P., Palme, K., Martin, F., Ditengou, F. A., and Legue, V. 2009. The ectomycorrhizal fungus Laccaria bicolor stimulates lateral root formation in poplar and Arabidopsis through auxin transport and signaling. Plant Physiol. 151:19912005.

Gervasi, S., Gondhalekar, C., Olson, D. H., and Blaustein, A. R. 2013. Host identity matters in the amphibian-Batrachochytrium dendrobatidis system: Fine scale patterns of variation in responses to a multi-host pathogen. PLoS One 8:e54490. Published online.

Gimenez-Ibanez, S., Boter, M., Fernandex-Barbero, G., Chini, A., Rathjen, J. P., and Solano, R. 2014. The bacterial effector HopX1 targets JAZ transcriptional repressors to activate jasmonate signaling and promote infection in Arabidopsis. PLoS Biol. 12:e1001792. Published online.

Gobbato, E., Marsh, J. F., Vernie, T., Wang, E., Maillet, F., Kim, J., Miller, J. B., Sun, J., Bano, S. A., Ratet, P., Mysore, K. S., Denarie, J. Schultze, M., and Oldroyd, G. E. D. 2012. A GRAS-type transcription factor with a specific function in mycorrhizal signaling. Curr. Biol. 22:2236-2241.

Heller, G., Adomas, A., Li, G., Osborne, J., van Zyl, L., Sederoff, R., Finlay, R. D., Stenlid, J. and Asiegbu, F. O. 2008. Transcriptional analysis of Pinus sylvestris roots challenged with the ectomycorrhizal fungus Laccaria bicolor. BMC Plant Biol. 8:19.

Herrera Medina, J., Gagnon, H., Piche, Y., Ocampo, J. A., Garcia, J. M., and Vierheilig, H. 2003. Root colonization by arbuscular mycorrhizal fungi is affected by the salicylic acid content of the plant. Plant Science 164:993-998

Hibbett, D. S., and Matheny, P. B. 2009. The relative ages of ectomycorrhizal mushrooms and their plant hosts estimated using Bayesian relaxed molecular clock analyses. BMC Biol. 7:13.

Jiang, S., Yao, J., Ma, K. W., Zhou, H., Song, J., He, S. Y., and Ma, W. 2013. Bacterial effector activates jasmonate signaling by directly targeting JAZ transcriptional repressors. PLoS Pathol. 9:e1003715. Published online.

Kaló, P., Gleason, C., Edwards, A., Marsh, J., Mitra, R. M., Hirsch, S., Jakab, J., Sims, S., Long, S. R., Rogers, J., Kiss, G. B., Downi, J. A., and Oldroyd, G. E. D. 2005. Nodulation signaling in legumes requires NSP2 a member of the GRAS family of transcription regulators. Science 308:1786-1789.

Kazan, K., and Lyons, R. 2014. Intervention of Phytohormone Pathways by Pathogen Effectors. Plant Cell 26:2285-2309.

Kemppainen, M., Dupessis, S., Martin, F., and Pardo, A. G. 2009. RNA silencing in the model mycorrhizal fungus Laccaria bicolor: Gene knock-down of nitrate reductase results in inhibition of symbiosis with Populus. Environ. Microbiol. 11 :1878-1896.

Khan, A. L., Waqas, M., Hamayun, M., Al-Harrasi, A., Al-Rawahhi, A., 
Lee, I.-J. 2013. Co-synergism of endophyte Penicillium resedanum LK6 with salicylic acid helped Capsicum annuum in biomass recovery and osmotic stress mitigation. BMC Microbiol. 13:51.

Kloppholz, S., Kuhn, H., and Requena, N. 2011. A secreted fungal effector of Glomus intraradices promotes symbiotic biotrophy. Curr. Biol. 21:1204-1209.

Kremer, N., Philipp, E. E. R., Carpentier, M.-C., Brennan, C. A., Kraemer, L., Altura, M. A., Augustin, R., Hasler, R., Heath-Heckman, E. A. C., Peyer, S. M., Schwatzman, J., Rader, B. A., Ruby, E. G., Rosenstiel, P. and McFall-Ngai, M. J. 2013. Initial symbiont contact orchestrates host-organ-wide transcriptional chages that prime tissue colonization. Cell Host Microbe 14:183-194.

Kim, Y. C., Kim, S. Y., Paek, K. H., Choi, D., and Park, J. M. 2006. Suppression of $C a C Y P 1$, a novel cytochrome $\mathrm{P} 450$ gene, compromises the basal pathogen defense response of pepper plants. Biochem. Biophys. Res. Commun. 30:638-645.

Labbé, J., Jorge, V., Kohler, A., Vion, P., Marcais, B., Bastien, C., Tuskan, G. A., Martin, F., and Le Tacon, F. 2011. Identification of quantitative trait loci affecting ectomycorrhizal symbiosis in an interspecific $F_{1}$ poplar cross and differential expression of genes in ectomycorrhizas of the two parents: Populus deltoides and Populus trichocarpa. Tree Genet. Genomes 7:617-627.

Larsen, P. E., Geetika, T., Sreedasyam, A., Lu, V., Podila, G. K., and Collart, F. R. 2010. Using deep RNA sequencing for the structural annotation of the Laccaria bicolor mycorrhizal transcriptome. PLoS One 5:e9780. Published online.

Larsen, P. E., Sreedasyam, A., Trivedi, G., Podila, G. K., Cseke, L. J., and Collart, F. R. 2011. Using next generation transcriptome sequencing to predict an ectomycorrhizal metabolome. BMC Syst. Biol. 13:70.

Le Tacon, F., Alvarez, I. F., Bouchard, D., Henrion, B., Jackson, R. M., Luff, S., Parlade, J. I., Pera, J., Stenstrom, E., Villeneuve, N., and Walker, C. 1992. Variations in field response of forest trees to nursery ectomycorrhizal inoculation in Europe. Pages 119-134 in: Mycorrhizas in Ecosystems 1992. CAB Internatational, Wallingford, U.K

Li, J., Brader, G., and Palva, E. T. 2004. The WRKY70 transcription factor: A node of convergence for jasmonate-mediated and salicylate-mediated signals in plant defense. Plant Cell 16:319-331.

Libault, M., Wan, J., Czechowski, T., Udvardi, M. and Stacey, G. 2007. Identification of 118 Arabidopsis transcription factor and 30 ubiquitinligase genes responding to chitin, a plant-defense elicitor. Mol. PlantMicrobe Interact. 20:900-911.

Limpens, E., Franken, C., Smit, P., Willemse, J., Bisseling, T., and Geurts, R. 2003. LysM domain receptor kinases regulating rhizobial Nod factor-induced infection. Science 302:630-633.

Luo, Z. B., Janz, D., Jiang, X., Gobel, C., Wildhagen, H., Tan, Y., Rennenberg, H., Feussner, I., Polle, A. 2009. Upgrading root physiology for stress tolerance by ectomycorrhizas: Insights from metabolite and transcriptional profiling into reprogramming for stress anticipation. Plant Physiol. 151:1902-1907.

Madsen, E. B., Madsen, L. H., Radutoiu, S., Olbryt, M., Rakwalska, M., Szczyglowski, K., Sato, S., Kaneko, T., Tabata, S., Sanda, N., and Stougaard, J. 2003. A receptor kinase gene of the LysM type is involved in legume perception of rhizobial signals. Nature 425:637-640.

Martin, F., Aerts, A., Ahrn, D., Brun, A., Danchin, E. G. J., Duchaussoy F., Gibon, J., Kohler, A., Lindquist, E., Pereda, V., Salamov, A., Shapiro, H. J., Wuyts, J., Blaudez, D., Buée, M., Brokstein, P., Canbäck, B., Cohen, D., Courty, P. E., Coutinho, P. M., Delaruelle, C., Detter, J. C., Deveau, A., DiFazio, S., Duplessis, S., Fraissinet-Tachet, L., Lucic, E., Frey-Klett, P., Fourrey, C., Feussner, I., Gay, G., Grimwood, J., Hoegger, P. J., Jain, P., Kilaru, S., Labbé, J., Lin, Y. C. Legué, V., Le Tacon, F., Marmeisse, R., Melayah, D., Montanini, B., Muratet, M., Nehls, U., Niculita-Hirzel, H., Oudot-Le Secq, M. P., Peter, M., Quesneville, H., Rajashekar, B., Reich, M., Rouhier, N., Schmutz, J., Yin, T., Chalot, M., Henrissat, B., Kües, U., Lucas, S., Van de Peer, Y., Podila, G. K., Polle, A., Pukkila, P. J., Richardson, P. M., Rouzé, P., Sanders, I. R., Stajich, J. E., Tunlid, A., Tuskan, G., and Grigoriev I. V. 2008. The genome sequence of Laccaria bicolor provides insights into the mycorrhizal symbiosis. Nature 452:88-92.

Martin, F., and Kamoun, S. 2012. Effectors in Plant-Microbe Interactions M. F, Kamoun S, ed. John Wiley \& Sons, Oxford, U.K

Mukhtar, M. S., Carvunis, A. R., Dreze, M., Epple, P., Steinbrenner, J., Moore, J., Tasan, M., Galli, M., Hao, T., Nishimura, M. T., Pevzner, S. J., Donovan, S. E., Ghamsari, L., Santhanam, B., Romero, V., Poulin, M. M., Gebreab, F., Gutierrez, B. J., Tam, S., Monachello, D., Boxem, M., Harbort, C. J., McDonald, N., Gai, L., Chen, H., He, Y., European Union Effectoromics Consortium, Vandenhaute, J., Roth, F. P., Hill, D. E., Ecker, J. R., Vidal, M., Beynon, J., Braun, P., and Dangl, J. L. 2011. Independently evolved virulence effectors converge onto hubs in a plant immune system network. Science 333:596-601.

Newton, A. C., Fitt, B. D., Atkins, S. D., Walters, D. R., and Daniell, T. J.
2010. Pathogenesis, parasitism and mutualism in the trophic space of microbe-plant interactions. Trend Microbiol. 18:365-373.

Oldroyd, G. E. 2013. Speak, friend, and enter: Signalling systems that promote beneficial symbiotic associations in plants. Nat. Rev. Microbiol. 11:252-263.

Plett, J. M., Kemppainen, M., Kale, S., Kohler, A., Legué, V., Brun, A., Tyler, B., Pardo, A., and Martin, F. 2011. A secreted effector protein of Laccaria bicolor is required for symbiosis development. Curr. Biol. 21:1197-1203

Plett, J. M., Daguerre, Y., Wittulsky, S, Vayssières, A., Deveau, A., Melton, S. J., Kohler, A., Morrell-Falvey, J., Brun, A., Veneault-Fourrey, C., and Martin, F. 2014a Effector MiSSP7 of the mutualistic fungus Laccaria bicolor stabilizes the Populus JAZ6 protein and represses jasmonic acid (JA)-responsive genes. Proc. Natl. Acad. Sci. U.S.A. 111; 8299-8304.

Plett, J.M., Khachane, A., Ouassou, M., Sundberg, B., Kohler, A., and Martin, F. 2014b. Ethylene and jasmonic acid act as negative modulators during mutualistic symbiosis between Laccaria bicolor and Populus roots. New Phytol. 202:270-286.

Reboutier, D., Bianchi, M., Brault, M., Roux, C, Daupin, A., Rona, J.-P., Legue, V., Lapeyrie, F., and Bouteau, F. 2002. The indolic compound hypaphorine produced by ectomycorrhizal fungus interferes with auxin action and evokes early responses in nonhost Arabidopsis thaliana. Mol. Plant Microbe Interact. 15:932-938.

Radutoiu, S., Madsen, L. H., Madsen, E. B., Felle, H. H., Umehara, Y., Gronlund, M., Sato, S., Nakamura, Y., Tabata, S., Sandal, N., and Stougaard, J. 2003. Plant recognition of symbiotic bacteria requires two LysM receptor-like kinases. Nature 425:585-592.

Shigenobu, S., Watanabe, H., Hattori, M., Sakaki, Y., and Ishikawa, H. 2000. Genome sequence of the endocellular baterial symbiont of aphids Buchnera sp. Nature 407:81-86.

Smit, P., Raedts, J., Portyanko, V., Debelle, R., Gough, C., Bisseling, T., and Geurts, R. 2005. NSP1 of the GRAS protein family is essential for rhizobial Nod factor-induced transcription. Science 308:1789-1791.

Tarkka, M. T., Herrmann, S., Wubet, T., Feldhahn. L., Recht, S., Kurth, F., Mailänder, S., Bönn, M., Neef, M., Angay, O., Bacht, M., Graf, M., Maboreke, H., Fleischmann, F., Grams, T. E., Ruess, L., Schädler, M., Brandl, R., Scheu, S., Schrey, S. D., Grosse, I., and Buscot, F. 2013. OakContigDF159.1, a reference library for studying differential gene expression in Quercus robur during controlled biotic interactions: Use for quantitative transcriptomic profiling of oak roots in ectomycorrhizal symbiosis. New Phytol. 199:529-540.

Thomma, B. P. H. J., Nürnberger, T., and Joosten, M. H. A. J. 2011. Of PAMPs and effectors: The blurred PTI-ETI dichotomy. Plant Cell 23:14-15

Tschaplinski, T. J., Plett, J. M., Engle, N. L., Deveau, A., Cushman, K. C., Martin, M. Z., Doktycz, M. J., Tuskan, G. A., Brun, A., Kohler, A., and Martin, F. 2014. Populus trichocarpa and Populus deltoides exhibit different metabolomic responses to colonization by the symbiotic fungus Laccaria bicolor. Mol. Plant Microbe Interact. 27:546-556.

Tuskan, G. A., Difazio, S., Jansson, S., Bohlmann, J., Grigoriev, I., Hellsten, U., Putnam, N., Ralph, S., Rombauts, S., Salamov, A., Schein, J., Sterck, L., Aerts, A., Bhalerao, R. R., Bhalerao, R. P,. Blaudez, D., Boerjan, W., Brun, A., Brunner, A., Busov, V., Campbell, M., Carlson, J., Chalot, M., Chapman, J., Chen, G. L., Cooper, D., Coutinho, P. M., Couturier, J., Covert, S., Cronk, Q., Cunningham, R., Davis, J., Degroeve, S., Déjardin, A., Depamphilis, C., Detter, J., Dirks, B., Dubchak, I., Duplessis, S., Ehlting, J., Ellis, B., Gendler, K., Goodstein, D., Gribskov, M., Grimwood, J., Groover, A., Gunter, L., Hamberger, B., Heinze, B., Helariutta, Y., Henrissat, B., Holligan, D., Holt, R., Huang, W., IslamFaridi, N., Jones, S., Jones-Rhoades, M., Jorgensen, R., Joshi, C. Kangasjärvi, J., Karlsson, J., Kelleher, C., Kirkpatrick, R., Kirst, M., Kohler, A., Kalluri, U., Larimer, F., Leebens-Mack, J., Leplé, J. C., Locascio, P., Lou, Y., Lucas, S., Martin, F., Montanini, B., Napoli, C., Nelson, D. R., Nelson, C., Nieminen, K., Nilsson, O., Pereda, V., Peter, G., Philippe, R., Pilate, G., Poliakov, A., Razumovskaya, J., Richardson, P., Rinaldi, C., Ritland, K., Rouzé, P., Ryaboy, D., Schmutz, J., Schrader, J., Segerman, B., Shin, H., Siddiqui, A., Sterky, F., Terry, A., Tsai, C. J., Uberbacher, E., Unneberg, P., Vahala, J., Wall, K,. Wessler, S., Yang, G., Yin, T., Douglas, C., Marra, M., Sandberg, G., Van de Peer, Y., and Rokhsar, D. 2006. The genome of black cottonwood, Populus trichocarpa (Torr. \& Gray). Science 313:1596-1604.

Van Ham, R. C. H. J., Kamerbeek, J., Palacios, C., Rausell, C., Abascal, F., Bastolla, U., Fernandez, J. M., Jimenez, L., Postigo, M., Silva, F. J., Tamames, J., Viguera, E., Latorre, A., Valenci, A., Moran, F., and Moya, A. 2003. Reductive genome évolution in Buchnera aphidicola Proc. Natl. Acad. Sci U.S.A. 100:581-586.

Wallenda, T., and Kottke, I. 1998. Nitrogen deposition and ectomycorrhizas. New Phytol. 139:169-187.

Wang, T., Chen, X., Zhu, F., Li, H., Li, L., Yang, Q., Chi, X., Yu, S., and Liang, X. 2013. Characterization of peanut germin-like proteins, 
AhGLPs in plant development and defense. PLoS One 8:e61722. Published online.

Weiler, E. W., Kutchan, T. M., Gorba, T., Brodschelm, W., Niesel, U., and Bublitz, F. 1994. The Pseudomonas phytotoxin coronatine mimics octadecanoid signaling molecules in higher plants. FEBS (Fed. Eur. Biochem. Soc.) Lett. 345:9-13.

Xiao, J.-H., Yue, Z., Jia, L.-Y., Yang, X.-H., Niu, L.-H., Wang, Z., Zhang, P., Sun, B. F., He, S. M., Li, Z., Xiong, T. L., Xin, W., Gu, H. F., Wang, B., Werren, J. H., Murphy, R. W., Wheeler, D., Niu, L. M., Ma, G. C., Tang, T., Bian, S. N., Wang, N. X., Yang, C. Y., Wang, N., Fu, Y. G., Li, W. Z., Yi, S. V., Yang, X. Y., Zhou, Q., Lu, C. X., Xu, C. Y., He, L. J., Yu, L. L., Chen, M., Zheng, Y., Wang, S. W., Zhao, S., Li, Y. H,. Yu ,Y. Y., Qian, X. J., Cai, Y., Bian, L. L., Zhang, S., Wang, J. Y., Yin, Y., Xiao, H., Wang, G. H., Yu, H., Wu, W. S., Cook, J. M., Wang, J., Huang, D.
W. 2013. Obligate mutualism within a host drives the extreme specialization of a fig wasp genome. Genome Biol. 14:R141.

Xu, L., Zhu, L., Tu, L., Liu, L., Yuan, D., Jin, L., Long, L., and Zhang, X. 2011. Lignin metabolism has a central role in the resistance of cotton to the wilt fungus Verticillium dahliae as revealed by RNA-Seq-dependent transcriptional analysis and histochemistry. J. Exp. Bot. 62:5607-5621.

\section{AUTHOR-RECOMMENDED INTERNET RESOURCES}

CyberT analysis tools: cybert.ics.uci.edu

ImageJ sever: imagej.nih.gov/ij/docs/index.html

National Center for Biotechnology Information's Gene Expression

Omnibus datatbase: www.ncbi.nlm.nih.gov/geo 